\title{
Effect of Grain Moisture Content on Rupture Force of Paddy
}

\author{
Prerana P. Jena ${ }^{1 *}$, A. K. Goel ${ }^{1}$, S. K. Swain ${ }^{1}$, R. R. Pattnaik ${ }^{2}$ and D. Behera ${ }^{1}$ \\ ${ }^{1}$ Department of Farm Machinery \& Power, College of Agricultural Engineering \\ \&Technology, OUAT, Bhubaneswar, India \\ ${ }^{2}$ Department of Agricultural Structures, Civil and Environmental Engineering, College of \\ Agricultural Engineering \& Technology, OUAT, Bhubaneswar, India
}

*Corresponding author

A B S T R A C T

Keywords

Rupture force, Grain moisture content, Loading rate, Paddy

Article Info

Accepted:

12 January 2021

Available Online:

10 February 2021
Determination of rupture force is essential before designing any threshing equipment. A study was conducted at College of Agricultural Engineering and Technology, OUAT, Bhubaneswar, India during Rabi 2020 to find rupture force of paddy grain. The grain rupture force of six varieties of paddy were determined at four levels of grain moisture content and three levels of loading rate by using Universal Testing Machine. The rupture force of each variety was determined at three loading rate of 10, 15 and 20 $\mathrm{mm}$ per min at same four levels of moisture content. It was observed that the rupture force decreased with increase in moisture content of paddy grain.

\section{Introduction}

Paddy (Oryza sativa L.) is an ancient cereal crop. In Odisha, about $70 \%$ of the population depend on agriculture. Out of the total cultivable land of 61.80 lakh hectare, paddy covers 38.80 and 3.00 lakh hectare in Kharif and Rabi season respectively (Anonymous, 2014-15). Threshing is an agricultural operations which is required to detach the grains from the bundle of panicles of any cereal crop particularly paddy and wheat. For developing a thresher, it is important to design the appropriate size of the threshing cylinder. For this purpose, the rupture force of grain is one of the important parameters that need to be considered. Hence, the recent study was undertaken to determine rupture strength of paddy by using Universal Testing machine (UTM).

Many researchers have studied rupture force of agricultural products. Ribeiro et al., (2019) assessed the mechanical properties of saccharine sorghum seeds at different moisture contents. Compressive tests were performed through uni-axial tests for a sample of 15 seeds at different moisture content. 
Their results indicated that the compressive force required to deform saccharine sorghum seeds decreased with increasing moisture content. They also mentioned that the reduction in moisture content caused an increase in the force required to rupture the seeds. Tavakoli et al., (2009) studied the effect of moisture content and loading rate on fracture resistance of barley grains. The barley grains were quasi-statically loaded with two levels of loading rates 5 and 10 $\mathrm{mm} / \mathrm{min}$ and four levels of moisture content $7.34,12.11,16.82$, and $21.58 \%$ dry basis. It was observed that the force required for initiating the grain rupture decreased from 161.97 to $93.94 \mathrm{~N}$ with the increase in the moisture content from 7.34 to $21.58 \%$ dry basis. Saiedirad et al., (2008) studied the effects of seed size, seed orientation, loading rate and moisture content on the force and energy required for fracturing cumin seed under quasi-static loading. Their results showed that seed rupture force decreased from 15.7 to $11.96 \mathrm{~N}$ with an increase in the moisture content from 5.7 to $15 \%$ dry basis. Konak et al., (2002) evaluated several physical properties of chick pea seeds as function of moisture content. He revealed that the rupture force decreased with the increase in the moisture content of the chick pea seeds. The highest rupture force of chick pea seed was reported as $210 \mathrm{~N}$ with a moisture content of $5.2 \%$ dry basis. Waananen and Okos (1988) studied failure properties of yellow-dent corn kernels under uni-axial compressive loading at four levels of temperature and moisture content. $\mathrm{He}$ revealed that the failure stress of corn decreased and failure strain increased when moisture content and temperature increased. Prasad and Gupta (1973) studied the behaviour of paddy grain under quasi-static compressive loading. He opined that the maximum compressive strength of paddy grain decreased with increase in moisture content. This study aimed to investigate the effect of moisture content and loading rate on the grain rupture force of different varieties of paddy prevailing in the state of Odisha by using Universal Testing Machine (make: Tinius Olsen, model: $5 \mathrm{kT}$, capacity: $5 \mathrm{kN}$ ).

\section{Materials and Methods}

This study was carried out in College of Agricultural Engineering and Technology, OUAT, Bhubaneswar, India. Local popular rice varieties namely Lalat and Pratibha (long grain), Birupa and Pratikshya (medium grain), Sidhanta and Hasanta (short grain) were taken for the study to find the rupture force of grain at various grain moisture contents. At the end of crop maturity, each paddy variety was harvested and collected from field. The panicles were randomly selected from the harvested paddy bundles and sealed in a plastic packet and tested on the same day in the laboratory.. The individual grain of each variety was loaded between the two cross head and the compression plate. The grain was kept on the lower compression plate and the cross head moves towards the lower fixture plate. When the grain gets compressed and cracked, the rupture force was recorded (Fig.1). After the experiment, the moisture content of paddy grain was measured by using grain moisture meter. Similarly, rupture force of all collected samples were determined. After sun drying of each variety for 4 hours, the experimental procedure was repeated. and three levels of loading rate $(50,100,150$ $\mathrm{mm} / \mathrm{min}$ ) and for determining the rupture force, the experiment was carried out at same four levels of moisture content (17.5 \pm 0.5 , $16.5 \pm 0.5,14.5 \pm 0.5$ and $13.5 \pm 0.5 \%)$ and three levels of loading rate $(10,15,20 \mathrm{~mm} / \mathrm{min})$.

\section{Results and Discussion}

The rupture force of different varieties of paddy at four levels of grain moisture content and three levels of loading rate was measured. 


\section{Rupture force of paddy grain}

The rupture force of grains of six paddy varieties namely Lalat, Pratibha, Birupa, Pratikshya, Sidhanta and Hasanta at four levels of moisture content were measured at three levels of loading rate $(10,15,20$ $\mathrm{mm} / \mathrm{min}$ ) and the results are presented in Table 1.

\section{Effect of moisture content on rupture force}

For paddy variety Lalat (long grain), the rupture force increased from 116.8 to $156.7 \mathrm{~N}$ at $10 \mathrm{~mm} / \mathrm{min}, 101.6$ to $144.1 \mathrm{~N}$ at $15 \mathrm{~mm} / \mathrm{min}$ and 88.2 to $121.8 \mathrm{~N}$ at $20 \mathrm{~mm} / \mathrm{min}$ as the moisture content decreased from 17.6 to $13.2 \%$. For paddy variety Birupa (medium grain), the rupture force increased from 18.6 to $167.5 \mathrm{~N}$ at $10 \mathrm{~mm} / \mathrm{min}, 99.3$ to $156.2 \mathrm{~N}$ at $15 \mathrm{~mm} / \mathrm{min}$ and 86.2 to $141.4 \mathrm{~N}$ at $20 \mathrm{~mm} / \mathrm{min}$ as the moisture content decreased from 17.6 to $13.8 \%$. Similarly for paddy variety Hasanta (short grain), the rupture force increased from 109.4 to $151.6,97.9$ to 140.5 and 85.4 to $129.8 \mathrm{~N}$ as the moisture content decreased from 17.7 to $13.3 \%$ at same loading rate variation of 10 to $20 \mathrm{~mm} / \mathrm{min}$ respectively.

Table.1 Rupture force $(\mathrm{N})$ of paddy grain at various loading rate

\begin{tabular}{|c|c|c|c|c|}
\hline \multirow[t]{3}{*}{ Variety } & \multirow{3}{*}{$\begin{array}{c}\text { Moisture } \\
\text { content, \% }\end{array}$} & \multirow{2}{*}{\multicolumn{3}{|c|}{$\begin{array}{l}\text { Loading rate, } \mathrm{mm} / \mathrm{min} \\
\text { Rupture force, } \mathrm{N}\end{array}$}} \\
\hline & & & & \\
\hline & & 10 & 15 & 20 \\
\hline \multirow[t]{4}{*}{ Lalat } & 17.6 & 116.8 & 101.6 & 88.2 \\
\hline & 16.4 & 128.9 & 112.9 & 97.6 \\
\hline & 14.4 & 142.6 & 135.7 & 106.4 \\
\hline & 13.2 & 156.7 & 144.1 & 121.8 \\
\hline \multirow[t]{4}{*}{ Pratibha } & 17.4 & 123.2 & 115.4 & 101.9 \\
\hline & 16.1 & 142.9 & 133.6 & 120.7 \\
\hline & 14.2 & 169.5 & 145.8 & 137.0 \\
\hline & 13.0 & 188.1 & 169.5 & 150.3 \\
\hline \multirow[t]{4}{*}{ Birupa } & 17.6 & 108.6 & 99.3 & 86.2 \\
\hline & 16.3 & 127.9 & 115.1 & 102.8 \\
\hline & 14.7 & 148.2 & 133.7 & 126.3 \\
\hline & 13.8 & 167.5 & 156.2 & 141.4 \\
\hline \multirow[t]{4}{*}{ Pratikshya } & 17.2 & 132.4 & 121.9 & 107.8 \\
\hline & 16.2 & 145.2 & 132.6 & 124.0 \\
\hline & 14.3 & 183.3 & 168.2 & 151.1 \\
\hline & 13.4 & 196.9 & 179.7 & 168.6 \\
\hline \multirow{4}{*}{ Sidhanta } & 17.8 & 134.0 & 120.1 & 109.3 \\
\hline & 16.7 & 147.9 & 132.4 & 121.8 \\
\hline & 14.9 & 157.3 & 145.6 & 133.9 \\
\hline & 13.6 & 178.6 & 167.7 & 156.8 \\
\hline \multirow{4}{*}{ Hasanta } & 17.7 & 109.4 & 97.9 & 85.4 \\
\hline & 16.6 & 121.3 & 111.4 & 101.9 \\
\hline & 14.5 & 144.9 & 132.5 & 126.3 \\
\hline & 13.3 & 151.6 & 140.5 & 129.8 \\
\hline
\end{tabular}


Table.2 Analysis of variance of rupture force of single grain

\begin{tabular}{|l|c|c|c|c|c|c|}
\hline Source of variation & $\begin{array}{c}\text { Degree of } \\
\text { freedom }\end{array}$ & $\begin{array}{c}\text { Sum of } \\
\text { squares }\end{array}$ & $\begin{array}{c}\text { Means of } \\
\text { squares }\end{array}$ & $\mathbf{F}_{\text {cal }}$ & \multicolumn{2}{|c|}{ C.D } \\
\hline Variety & 5 & 29453.254 & 5890.651 & 7201.2074 & 0.393388 & 0.29787 \\
\hline Grain moisture content & 3 & 80163.028 & 26721.009 & 32665.9207 & 0.321341 & 0.243316 \\
\hline Variety x moisture content & 15 & 3522.977 & 234.865 & 287.1181 & 0.787036 & 0.595937 \\
\hline Loading rate & 2 & 24702.076 & 12351.038 & 15098.9067 & 0.278269 & 0.210703 \\
\hline Variety x loading rate & 10 & 634.948 & 63.495 & 77.6212 & 0.681576 & 0.516084 \\
\hline $\begin{array}{l}\text { Grain moisture content } \mathbf{l} \\
\text { loading rate }\end{array}$ & 6 & 173.069 & 28.845 & 35.2622 & 0.556538 & 0.421406 \\
\hline $\begin{array}{l}\text { Variety x grain moisture } \\
\text { content x loading rate }\end{array}$ & 30 & 835.074 & 27.836 & 34.0287 & 1.363152 & 1.032167 \\
\hline Error & 144 & 117.793 & 0.818 & & & \\
\hline Total & 215 & 139602 & & & & \\
\hline
\end{tabular}

Coefficient of variation: $0.68 \%$

Fig.1 Measurement of rupture force of grain by Universal Testing Machine

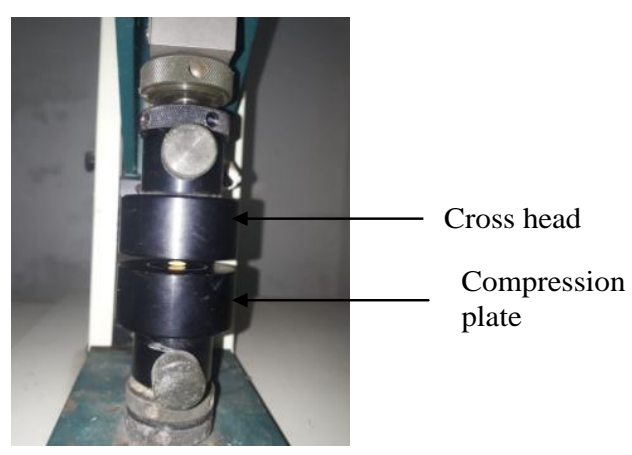

Fig.2 Rupture force of grain of different varieties at various moisture content
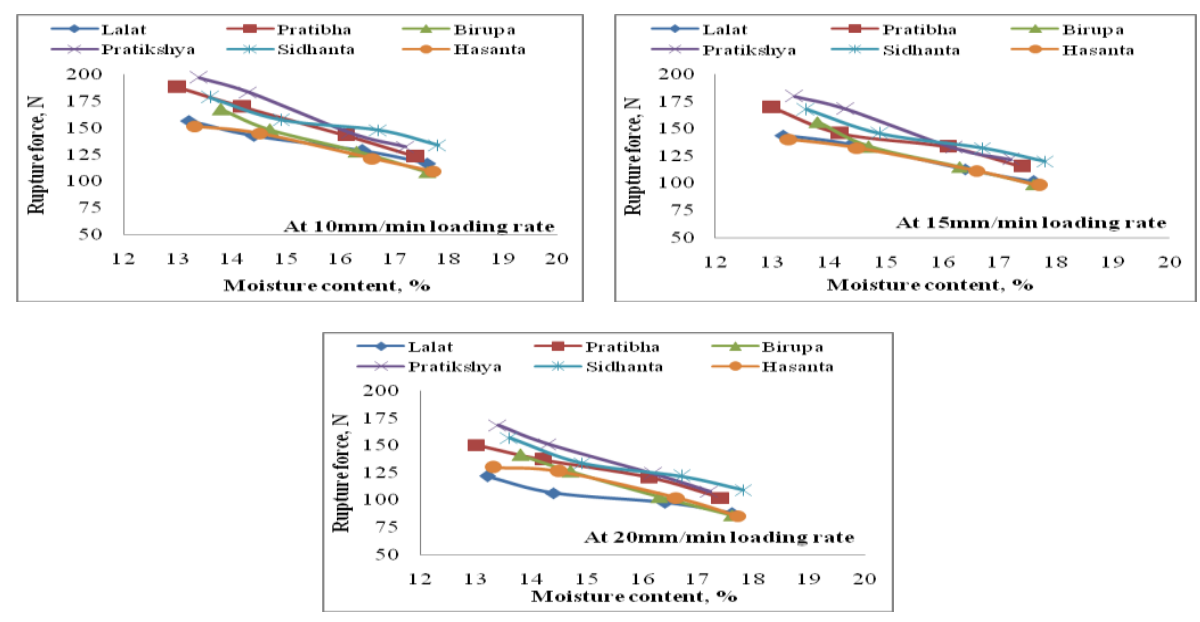
Fig.3 Rupture force of single grain of different varieties at various loading rate
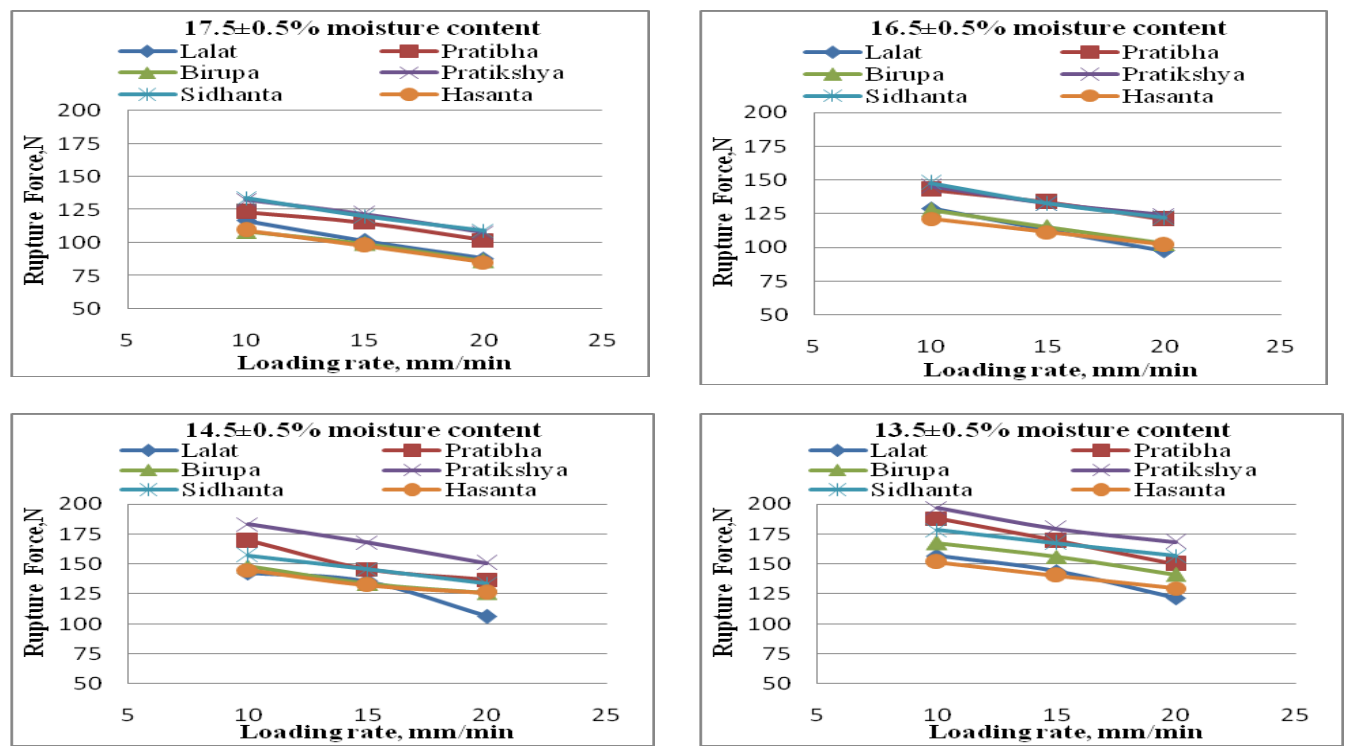

Similar trends were observed for all varieties of paddy grains at four levels of moisture content at three levels of loading rate (Fig.2). It was observed that the rupture force increased with decrease in grain moisture content. This may be due to the fact that at higher moisture content, the grain became softer and required less force while at lower moisture content, grain becme harder and require higher force to rupture. Such behaviour can be related to higher cellular density that occurred with reduction of moisture content from the grain i.e. as number of cells per unit volume increased; it resulted in a greater resistance to compression at lower moisture contents. This conclusion is in agreement with the findings of Ribeiro et al., (2019) and Kotak et al., (2002).

\section{Effect of loading rate on rupture force}

The effect of loading rate on the rupture force of single grain was determined at three levels of loading rate of 10, 15 and $20 \mathrm{~mm} / \mathrm{min}$. For paddy variety Lalat (long grain), the rupture force decreased from 116.8 to $88.2,128.9$ to 97.6, 142.6 to 106.4 and 156.7 to $121.8 \mathrm{~N}$ as

loading rate increased from 10 to $20 \mathrm{~mm} / \mathrm{min}$ at $17.6,16.4,14.4,13.2 \%$ moisture content respectively. For paddy variety Birupa (medium grain), the rupture force decreased from 108.6 to $86.2,127.9$ to $102.8,148.2$ to 126.3 and 167.5 to $141.4 \mathrm{~N}$ as loading rate increased from 10 to $20 \mathrm{~mm} / \mathrm{min}$ at 17.6 , 16.3, 14.7 and $13.8 \%$ moisture content. Similarly for paddy variety Sidhanta (short grain), the rupture force decreased from 134.0 to $109.3,147.9$ to $121.8,157.3$ to 133.9 and 178.6 to $156.8 \mathrm{~N}$ when loading rate varied from 10 to $20 \mathrm{~mm} / \mathrm{min}$ at $17.8,16.7,14.9$ and $13.6 \%$ moisture content respectively. Similar trends were also observed for all varieties of paddy grain at various moisture contents when loading rate increased (Fig.3). It was observed that the rupture force decreased with increase in loading rate at all four levels of moisture contents. This finding is consistent with the result presented by Tavakoli et al., (2009).

The analysis of variance (ANOVA) of grain rupture force of different varieties is presented in Table 2. 
From table 2, it was seen that the variety, grain moisture content and loading rates have significant effect on rupture strength of grain. The interaction between variety and moisture content, variety and loading rate, moisture content and loading rate have significant effect on rupture strength. Also, the combined effect of variety, moisture content and loading rates has significant effect on rupture strength of grain.

In conclusion the rupture force of single grain of six popular varieties of paddy in the state were determined at four levels of grain moisture content varying from 13.0 to $17.8 \%$ by using UTM. The grain rupture force for each variety was undertaken at three levels of loading rate of 10,15 and $20 \mathrm{~mm} / \mathrm{min}$ at same four levels of moisture content. The following conclusions were drawn from this study.

The rupture force decreased as the grain moisture content and loading rate increased.

The maximum rupture force $(196.9 \mathrm{~N})$ obtained for Pratikshya variety at lowest moisture content of $13.4 \%$ at lowest loading rate of $10 \mathrm{~mm} / \mathrm{min}$ while the minimum force $(85.4 \mathrm{~N})$ required for Hasanta variety at higher loading rate of $20 \mathrm{~mm} / \mathrm{min}$ at highest moisture content of $17.7 \%$.

\section{References}

Anonymous. 2013-14. Odisha Agriculture Statistics, Directorate of Agriculture and Food Production, Odisha,
Bhubaneswar

Anonymous. 2014-15. Status of Agriculture in Odisha, Directorate of Agriculture and Food Production, Odisha, Bhubaneswar

Konak M., Carman K., Aydin C., 2002. Physical properties of chick pea seeds. Biosystem Engineering, 82: 73-78.

Prasad S., Gupta C.P., 1973. Behavior of paddy grains under quasistatic compressive loading. Transactions of the ASAE, 16: 328-330.

Ribeiro L.K.M., Taveira J.H.S., Silva P.C., Resend O.' Oliveira D.E.C., Costa A.R. 2019. Mechanical properties of saccharine sorghum (Sorghum bicolour L. Moench) seeds. Idesia, 37:11-17.

Saiedirad M.H., Tabatabaeefar A., Borghei A., Mirsalehi M., Badii F., Ghasemi Varnamkhasti M., 2008. Effects of moisture content, seed size, loading rate and seed orientation on force and energy required for fracturing cumin seed (Cuminum cyminum Linn.) under quasi-static loading. Journal of Food Engineering, 86: 565-572.

Tavakoli H., Mohtasebi S.S., Rajabipour A., Tavakoli M.,2009. Effects of moisture content, loading rate, and grain orientation on fracture resistance of barley grain. Res. Agr. Eng., 55: 85-93.

Waananen K.M., Okos M.R., 1988. Failure properties of yellow dent corn kernels. Transactions of the ASAE, 31: 18161823, 1827.

\section{How to cite this article:}

Prerana P. Jena, A. K. Goel, S. K. Swain, R. R. Pattnaik and Behera, D. 2021. Effect of Grain Moisture Content on Rupture Force of Paddy. Int.J.Curr.Microbiol.App.Sci. 10(02): 346-351. doi: https://doi.org/10.20546/ijcmas.2021.1002.040 